БАЛАЦКИЙ Евгений Всеволодович - доктор экономических наук, главный научный сотрудник Центрального экономико-математического института РАН; директор иентра макроэкономических исследований Финансового университета при Правительстве РФ (109456, РФ, г. Москва, 4-й Вешняковский пр-д, 4; evbalatsky@inbox.ru)

ЕКИМОВА Наталья Александровна - кандидат экономических наук, доцент; ведущий научный сотрудник иентра макроэкономических исследований Финансового университета при Правительстве РФ (109456, Россия, г. Москва, 4-й Вешняковский пр-д, 4; NAEkimova@fa.ru)

\title{
БУДУЩЕЕ РОССИЙСКОЙ ЭКОНОМИКИ ГЛАЗАМИ ВЛАСТЕЙ
}

\begin{abstract}
Аннотация. В статье рассматриваются принципиальные противоречия Прогноза социально-экономического развития Российской Федерации на 2021 год и на плановый период 2022 и 2023 годов. Авторы доказывают, что власти явно переоценивают будущую динамичность национальной экономики и устойчивость курса рубля на фоне предполагаемой полной стагнации отраслевой структуры ВВП и ослабления позиций обрабатывающего сектора. Очевидно, что данная картина будущего нуждается в серьезной корректировке.
\end{abstract}

Ключевые слова: прогнозирование, планирование, экономический рост

Введение. В настоящий момент мир переживает период глобальной турбулентности, когда старый миропорядок утратил свою эффективность и идет его переформатирование [Валлерстайн 2006]. Однако контуры нового формата пока не определены. Такая ситуация в отношении всех государств и народов порождает жесткий цивилизационный вызов: каково будет их место в новом мире? Разумеется, этот вызов адресован прежде всего властным национальным элитам, которые должны сформировать свой ответ на него. Для ответа на столь масштабный вызов власть должна иметь в своем распоряжении по-настоящему эффективную систему государственного управления [Тойнби 2011].

Сказанное полностью приложимо и к российской властной элите, которая должна найти свою модель развития страны, способную обеспечить ей достойное место в геополитическом пространстве. Отчасти ответ на возникший вызов призваны дать прогнозные документы правительства страны. Разработка таковых возложена на Минэкономразвития России, которое готовит ежегодный прогноз на очередные несколько лет. Не является исключением из этого правила и нынешний Прогноз социально-экономического развития Российской Федерации на 2021 год и на плановый период 2022 и 2023 годов (далее Прогноз-2021) 1 . Хотя данный документ не носит нормативный характер и указанные в нем цифры не обязательны к выполнению, он все-таки показывает, во-первых, видение российскими властями общей экономической ситуации в стране в ближайшие 3 года, во-вторых, приоритеты и зоны пристального интереса правительства, в-третьих, направления и масштабы действий регулятора. Все это вызывает пристальное внимание и обсуждение в среде аналитиков [Масленников и др. 2019].

Каким же видится экономическое будущее российской экономики нынешней власти?

Цель статьи состоит в ответе на поставленный вопрос с помощью прави-

\footnotetext{
1 Прогноз социально-экономического развития Российской Федерации на 2021 год и на плановый период 2022 и 2023 годов. Доступ: https://www.economy.gov.ru/material/file/956cd e638e96c25da7d978fe3424ad87/Prognoz.pdf(проверено 08.01.2021).
} 
тельственного документа Прогноз-2021. Своеобразие поставленной проблеме придает специфика периода подготовки и обнародования документа - 2020 год, который прошел под знаком вируса $C O V I D-19$ и связанных с ним ограничений, повлекших грандиозное охлаждение мировой экономики. Разумеется, подготовка Прогноза-2021 в разгар бушующей пандемии предопределила массу объективных недостатков документа. Тем не менее Прогноз-2021 призван обозначить реперные точки ближайшего будущего России. Рассмотрим их подробнее и определим, насколько они достижимы.

Необоснованный оптимизм. Прогноз-2021 составлен в двух вариантах - базовом и консервативном, которые в целом отражают сложившуюся кризисную ситуацию в мире и России. Однако консервативный вариант основан на предпосылках о менее благоприятной санитарно-эпидемиологической ситуации.

Для начала рассмотрим два показателя, которые в Прогнозе-2021 учитываются в качестве исходных условий формирования вариантов развития экономики: это темпы роста экономики и среднегодовой курс доллара США. За основу возьмем показатели базового сценария, т.к. именно он, по мнению разработчиков, является наиболее вероятным.

Согласно Прогнозу-2021, ожидаемый рост ВВП в ближайшие 3 года должен составить не меньше 3,0\% ежегодно (см. табл. 1). Реально это или нет?

Если обратиться к ретроспективе за последние 8 лет, то можно увидеть, что, во-первых, начиная с 2013 г., рост ВВП даже при более благоприятных условиях не достигал подобных значений, а, во-вторых, с учетом спада 2020 г. линия ретроспективного тренда становится вообще убывающей (см. табл. 1). Иными словами, простая ретроспективная экстраполяция указывает на недостижимость прогнозных темпов роста ВВП.

Таблица 1

Годовая динамика ВВП России, \%

\begin{tabular}{|l|c|c|c|c|c|c|c|c|c|c|c|}
\hline \multirow{2}{*}{ Годы } & \multicolumn{5}{|c|}{ Ретроспектива } & \multicolumn{3}{|c|}{ Н/в } & \multicolumn{3}{|c|}{ Перспектива } \\
\cline { 2 - 12 } & $\mathbf{2 0 1 3}$ & $\mathbf{2 0 1 4}$ & $\mathbf{2 0 1 5}$ & $\mathbf{2 0 1 6}$ & $\mathbf{2 0 1 7}$ & $\mathbf{2 0 1 8}$ & $\mathbf{2 0 1 9}$ & $\mathbf{2 0 2 0}$ & $\mathbf{2 0 2 1}$ & $\mathbf{2 0 2 2}$ & $\mathbf{2 0 2 3}$ \\
\hline $\begin{array}{l}\text { Темпы } \\
\text { Прироста } \\
\text { ВВП }\end{array}$ & 1,8 & 0,7 & $-2,0$ & 0,2 & 1,8 & 2,5 & 1,3 & $-3,9$ & 3,3 & 3,4 & 3,0 \\
\hline
\end{tabular}

Источник: Росстат; Прогноз-2021.

Если перейти к среднегодовым значениям темпов экономического роста 7 ретроспективных лет и 3 прогнозных, то сделанный вывод станет почти очевидным (см. табл. 2). Российский регулятор предполагает в несколько раз повысить динамичность отечественной экономики по сравнению с предыдущим периодом. При этом прогнозные оценки не учитывают ни закрытость мировой экономики из-за COVID-19 и неочевидность ее открытия в следующие годы, ни восстановительный характер роста ВВП, ни экономические меры поддержки со стороны государства, ни стимулирующие меры денежнокредитной и фискальной политики. Все это происходит по умолчанию на уровне скорее пожелания, нежели прогнозирования. Тем самым излишне оптимистичные прогнозируемые темпы роста ВВП предопределены тем фактом, что Прогноз-2021 выступает не столько в качестве «чистого» прогнозного документа, сколько в качестве нетрадиционного инструмента планирования, в который закладываются скорее желаемые экономические параметры, которых надо достигнуть даже вопреки неблагоприятной конъюнктуре, чем расчетные. 
Под прогнозный сценарий разрабатывается бюджет страны и отчасти политика Банка России.

Таблииа 2

Интервальная динамика ВВП России, \%

\begin{tabular}{|c|c|c|c|}
\hline \multirow{2}{*}{ Годы } & \multicolumn{2}{|c|}{ Период } & \multirow{2}{*}{ Разрыв, раз } \\
\cline { 2 - 3 } & $\mathbf{2 0 1 3 - 2 0 1 9}$ & $\mathbf{2 0 2 1 - 2 0 2 3}$ & \\
\hline Средние темпы прироста ВВП & 0,90 & 3,23 & 3,6 \\
\hline
\end{tabular}

Источник: Росстат; Прогноз-2021.

Другим проявлением необоснованного оптимизма являются и прогнозируемые значения показателя среднегодового курса доллара в рублевом эквиваленте. Это опять-таки наглядно видно при сравнении трех до- и послекороновирусных годов (см. табл. 3). Даже невооруженным глазом видно, что регулятор явно переоценил ситуацию в коронавирусный год (первое число - прогноз, второе - факт на ноябрь 2020 г.) и предполагает слишком медленное обесценение рубля в последующий период.

Таблица 3

Годовая динамика валютного курса рубль/доллар

\begin{tabular}{|c|c|c|c|c|c|c|c|}
\hline \multirow{2}{*}{ Годы } & \multicolumn{3}{|c|}{ Ретроспектива } & Н/в & \multicolumn{3}{c|}{ Перспектива } \\
\cline { 2 - 8 } & $\mathbf{2 0 1 7}$ & $\mathbf{2 0 1 8}$ & $\mathbf{2 0 1 9}$ & $\mathbf{2 0 2 0}$ & $\mathbf{2 0 2 1}$ & $\mathbf{2 0 2 2}$ & $\mathbf{2 0 2 3}$ \\
\hline Курс руб./долл. & 58,3 & 62,8 & 64,6 & $71,2 / 75,5$ & 72,4 & 73,1 & 73,8 \\
\hline
\end{tabular}

Источник: Банк России; Прогноз-2021.

Как и в предыдущем примере, ситуация становится более наглядной, если перейти к среднегодовым величинам подорожания доллара США (см. табл. 4). Несложно видеть, что Прогноз-2021 парадоксальным образом предполагает столь же масштабное улучшение динамики валютного курса, как и темпов экономического роста. При этом очевидно, что риски всех видов в предстоящие 3 года возрастут, в связи с чем рост стабильности рубля кажется скорее пожеланием властей, нежели объективным прогнозом.

Таблица 4

Интервальная динамика валютного курса рубль/доллар

\begin{tabular}{|c|c|c|c|}
\hline \multirow{2}{*}{ Годы } & \multicolumn{2}{|c|}{ Период } & \multirow{2}{*}{ Разрыв, раз } \\
\cline { 2 - 3 } & $\mathbf{2 0 1 7 - 2 0 1 9}$ & $\mathbf{2 0 2 1 - 2 0 2 3}$ & \\
\hline Среднегодовое удорожание доллара, руб. & 3,15 & 0,87 & $-3,6$ \\
\hline
\end{tabular}

Источник: Банк России; Прогноз-2021.

Упрощенное видение динамики рынка нефти. Еще одним примером несовершенства Прогноза-2021 являются заложенные в него показатели российской добычи нефти, в которых недоучтена ситуация, сложившаяся на миро- 
вом нефтяном рынке, где в апреле 2020 г. странами ОПЕК+ была согласована сделка о сокращении добычи нефти на ближайшие 2 года. Исходя из достигнутых соглашений, в России добыча нефти в 2021 г. предположительно составит 475,8 млн т, что на $8,1 \%$ меньше заложенного в Прогнозе-2021 исходного условия по добыче нефти в 2021 г. (517,8 млн т). Кроме того, недоучет ретроспективных тенденций также может провоцировать ошибки в прогнозных цифрах. Так, расчеты по 2022 г. показывают следующее: исходя из заложенных в Прогнозе-2021 показателей, ежедневная добыча нефти после прекращения действия сделки ОПЕК+ в конце апреля 2022 г. составит порядка 1,62 млн т/сутки, что на фоне достижений прошлого периода (например, 2019 г., когда добыча нефти в России достигла своего исторического максимума за весь постсоветский период и составила 1,53 млн т/сутки) выглядит слишком большим значением и технически сложно выполнимым. Если принять во внимание указанные объемы добычи нефти в сутки во второй половине 2022 г., также остается непонятным их прогнозное снижение в 2023 г. до «старых» значений 2019 г. $-1,53$ млн т/сутки $(560,0 / 365)$.

Нельзя не отметить и то обстоятельство, что прекращение сделки ОПЕК+ в 2022 г., если не будет принято новых соглашений подобного рода, приведет в росту мировой добычи нефти, что неминуемо скажется на ее цене. Однако, судя по Прогнозу-2021, сильных колебаний мировой цены на нефть марки Urals в 2022 г. не ожидается, что представляется маловероятным.

Необоснованный пессимизм. Рассмотрим примеры совершенно иного типа прогнозных ошибок - в сторону необоснованного пессимизма и недооценки динамичности отечественной экономики и ее элементов. В частности, обращает на себя внимание явный недоучет структурных изменений в российской экономике. Так, в Прогнозе-2021 на фоне довольно быстрого экономического роста предусмотрена полная стагнация отраслевой структуры ВВП, отраслевые доли которой практически не меняются на протяжении 5 лет: 2019-2023 гг. (см. табл. 5).

Таблица 5

Структура компонентов производства ВВП

\begin{tabular}{|l|c|c|c|c|c|}
\hline \multirow{2}{*}{ Доля отрасли в произведенном ВВП, \% } & \multicolumn{5}{|c|}{ Годы } \\
\cline { 2 - 7 } & $\mathbf{2 0 1 9}$ & $\mathbf{2 0 2 0}$ & $\mathbf{2 0 2 1}$ & $\mathbf{2 0 2 2}$ & $\mathbf{2 0 2 3}$ \\
\hline $\begin{array}{l}\text { Сельское, лесное хозяйство, охота, } \\
\text { рыболовство и рыбоводство }\end{array}$ & 3,4 & 3,6 & 3,5 & 3,4 & 3,4 \\
\hline Добыча полезных ископаемых & 11,3 & 9,4 & 9,4 & 9,5 & 9,3 \\
\hline Обрабатывающие производства & 13,1 & 13,4 & 13,3 & 13,2 & 13,2 \\
\hline $\begin{array}{l}\text { Обеспечение электрической энергией, газом и } \\
\text { паром; кондиционирование воздуха }\end{array}$ & 2,3 & 2,4 & 2,4 & 2,3 & 2,3 \\
\hline $\begin{array}{l}\text { Водоснабжение; водоотведение, организация } \\
\text { сбора и утилизации отодов, деятельность по } \\
\text { ликвидации загрязнений }\end{array}$ & 0,4 & 0,5 & 0,4 & 0,4 & 0,4 \\
\hline Строительство & 5,1 & 5,4 & 5,3 & 5,3 & 5,4 \\
\hline $\begin{array}{l}\text { Торговля оптовая и розничная; ремонт } \\
\text { автотранспортных средств и мотоциклов }\end{array}$ & 12,3 & 12,4 & 12,4 & 12,4 & 12,4 \\
\hline Транспортировка и хранение & 5,9 & 5,9 & 5,9 & 5,9 & 5,9 \\
\hline $\begin{array}{l}\text { Деятельность гостиниц и предприятий } \\
\text { общественного питания }\end{array}$ & 0,8 & 0,7 & 0,8 & 0,8 & 0,8 \\
\hline
\end{tabular}




\begin{tabular}{|c|c|c|c|c|c|}
\hline Деятельность в области информации и связи & 2,3 & 2,3 & 2,3 & 2,4 & 2,4 \\
\hline Деятельность финансовая и страховая & 3,8 & 3,6 & 3,7 & 3,7 & 3,8 \\
\hline $\begin{array}{l}\text { Деятельность по операциям с недвижимым } \\
\text { имуществом }\end{array}$ & 8,5 & 8,5 & 8,6 & 8,7 & 8,8 \\
\hline $\begin{array}{l}\text { Деятельность профессиональная, научная и } \\
\text { техническая }\end{array}$ & 3,9 & 3,9 & 4,0 & 4,1 & 4,2 \\
\hline $\begin{array}{l}\text { Деятельность административная и } \\
\text { сопутствующие дополнительные услуги }\end{array}$ & 1,9 & 1,9 & 1,9 & 1,8 & 1,8 \\
\hline $\begin{array}{l}\text { Государственное управление и обеспечение } \\
\text { военной безопасности; социальное } \\
\text { обеспечение }\end{array}$ & 6,7 & 8,0 & 7,8 & 7,6 & 7,5 \\
\hline Образование & 2,9 & 3,0 & 3,0 & 3,0 & 3,1 \\
\hline $\begin{array}{l}\text { Деятельность в области здравоохранения и } \\
\text { социальных услуг }\end{array}$ & 3,1 & 3,4 & 3,3 & 3,3 & 3,4 \\
\hline $\begin{array}{l}\text { Деятельность в области культуры, спорта, } \\
\text { организации досуга и развлечений }\end{array}$ & 0,9 & 1,0 & 1,0 & 1,0 & 1,0 \\
\hline Предоставление прочих видов услуг & 0,5 & 0,5 & 0,5 & 0,5 & 0,5 \\
\hline $\begin{array}{l}\text { Деятельность домашних хозяйств как } \\
\text { работодателей; недифференцированная } \\
\text { деятельность частных домашних хозяйств }\end{array}$ & 0,6 & 0,6 & 0,6 & 0,5 & 0,5 \\
\hline Чистые налоги на продукты и импорт & 10,4 & 9,8 & 10,0 & 10,1 & 10,0 \\
\hline
\end{tabular}

Источник: Прогноз-2021.

Тем самым прогнозный документ по умолчанию консервирует нынешнюю низкотехнологичную структуру российской экономики, что говорит об отрицании какого-либо технологического прогресса в ближайшие годы, предусмотренного в иных государственных нормативных актах, в т.ч. и в указе Президента РФ 2018 г. «О национальных целях и стратегических задачах развития Российской Федерации на период до 2024 года».

Не менее настораживающей представляется заложенная в Прогнозе-2021 абсолютно деструктивная тенденция, связанная с соотношением темпов роста ВВП и обрабатывающих производств. Согласно данным документа, имеет место следующая картина: до 2020 г. обрабатывающие производства были в 2 раза динамичнее ВВП, в 2020 г. они продемонстрировали высокую сопротивляемость кризису, после 2020 г. предполагаемая динамичность обрабатывающей промышленности будет отставать от динамики ВВП (в среднем 3,1\% против 3,2\%) (см. табл. 6).

Таблица 6

Сравнение динамики ВВП и обрабатывающего производства

\begin{tabular}{|c|c|c|c|c|c|}
\hline \multirow{2}{*}{ Темпы прироста, \% } & \multicolumn{5}{|c|}{ Годы } \\
\cline { 2 - 6 } & $\mathbf{2 0 1 9}$ & $\mathbf{2 0 2 0}$ & $\mathbf{2 0 2 1}$ & $\mathbf{2 0 2 2}$ & $\mathbf{2 0 2 3}$ \\
\hline ВВП & 1,3 & $-3,9$ & 3,3 & 3,4 & 3,0 \\
\hline Обрабатывающие производства & 2,6 & $-1,5$ & 3,1 & 3,0 & 3,3 \\
\hline
\end{tabular}

Источник: Прогноз-2021.

Прогнозный парадокс с динамикой обрабатывающих производств означает, 
что на них не возлагается роль драйвера российской экономики. Это особенно странно в период становления совершенно нового типа обрабатывающих производств. В такой ситуации справедливо спросить: а какие же отраслевые драйверы экономики видят российские власти? Прогноз-2021 дает весьма примитивный ответ на данный вопрос: наиболее динамично будут развиваться следующие отрасли: производство лекарственных средств (темпы прироста за период 2019-2023 гг. составят 42,4\%); производство химических веществ $24,9 \%$; производство компьютеров, электронных и оптических изделий $20,8 \%$. В отношении первой позиции сомнений быть не может, особенно в условиях вирусного ажиотажа [Наджафова 2019; Крестьянинов 2018]; в отношении второй также ничего нового нет, ибо химическая промышленность в России была всегда среди самых благополучных [Бахарев и др. 2018; Кулясова 2019]; в отношении третьей не стоит обольщаться, ибо ее масштаб настолько мал, что ее прогнозируемая динамичность связана в основном с эффектом низкой базы [Гавловская, Хакимов 2019; Оболенская, Морева 2019].

Заключение. Рассмотренные особенности Прогноза-2021 свидетельствуют о дезориентации власти даже по отношению к ближайшему будущему, что проявляется в противоречивости самого прогнозного документа. На фоне достаточно динамичного развития всей экономики и устойчивого курса рубля предполагается полная стагнация ее отраслевой структуры и «увядание» обрабатывающего сектора промышленности.

Сказанное предполагает необходимость пересмотра параметров Прогноза-2021 и их корректировки в сторону более реалистичных значений и более строгой увязки между собой. Речь идет о пересмотре документа в рабочем режиме и использовании его обновленной версии хотя бы для внутренних административных решений.

\footnotetext{
Статья подготовлена в рамках государственного задания Правительства Российской Федерации Финансовому университету на 2021 год по теме «Технологические, структурные и социальные факторы долгосрочного экономического роста» (АAAA-A19-119080990043-0).
}

\section{Список литературы}

Бахарев В.В., Дюкарева Ю.П., Конников Е.А., Конникова О.А., Ходосов К.А. 2018. Химическая промышленность в России (анализ развития 2005-2017 год). - Экономические науки. № 179. С. 31-37.

Валлерстайн И. 2006. Миросистемный анализ: Введение. М.: ИД «Территория будущего». 248 с.

Гавловская Г.В., Хакимов А.Н. 2019. Тенденции развития электронной промышленности России. - Экономика и предпринимательство. № 1(102). С. $105-$ 110.

Крестьянинов Н.А. 2018. Анализ мер государственного стимулирования инвестиций в российскую фармацевтическую промышленность. - Экономика: вчера, сегодня, завтра. Т. 8. № 8А. С. 63-77.

Кулясова Е.В. 2019. Химическая промышленность России: современное состояние и проблемы развития - Вестник университета. № 5. С. 93-100.

Масленников В.В. и др. 2019. Оценка Прогноза социально-экономического развития Российской Федерации на период 2019-2024 годов (сентябрь, 2019 г.) - Финансы: теория и практика. Т. 23. № 5. С. 126-130.

Наджафова М.Н. 2019. О развитии фармацевтической промышленности РФ. - Карельский научный журнал. Т. 8. № 1(26). С. 86-89. 
Оболенская Л.В., Морева Е.Л. 2019. Проблемы развития высокотехнологичного сектора российской промышленности. - Друкеровский вестник. № 5(31). C. 63-74.

Тойнби А.Дж. 2011. Цивилизация перед судом истории. Мир и Запад. М.: АСТ; Астрель. 318 с.

BALATSKY Evgeniy Vsevolodovich, Dr.Sci. (Econ.), Professor, Chief Researcher of the Central Economic Mathematical Institute, Russian Academy of Sciences, Director of the Center for Macroeconomic Research, Department of Macroeconomic Forecasting and Planning, Financial University under the Government of the Russian Federation, (4, $4^{\text {th }}$ Veshnyakovsky Pass, Moscow, Russia, 109456; evbalatsky@inbox.ru)

EKIMOVA Natalia Aleksandrovna, Cand.Sci. (Econ.), Associate Professor, Leading Researcher of the Center for Macroeconomic Research, Department of Macroeconomic Forecasting and Planning, Financial University under the Government of the Russian Federation (4, $4^{\text {th }}$ Veshnyakovsky Pass, Moscow, Russia, 109456; NAEkimova@fa.ru)

\section{FUTURE OF THE RUSSIAN ECONOMY IN THE EYES OF AUTHORITIES}

Abstract. The article considers the fundamental contradictions in the Forecast of Socio-Economic Development of the Russian Federation for 2021 and for the Planning Period of 2022 and 2023. The authors show that the authorities clearly overestimate the future dynamism of the national economy and the stability of the ruble exchange rate on the background of the expected complete stagnation of the sectoral structure of GDP and the weakening position of the manufacturing sector. The authors substantiate that this picture of the future needs serious adjustment.

Keywords: forecasting, planning, economic growth 